\title{
Two years survival rate of class II composite resin restorations prepared by ART with and without a chemomechanical caries removal gel in primary molars
}

\author{
Asli Topaloglu-Ak • Ece Eden • Jo E. Frencken • \\ Ozant Oncag
}

Received: 7 February 2008 / Accepted: 5 December 2008/Published online: 20 December 2008

(C) The Author(s) 2008. This article is published with open access at Springerlink.com

\begin{abstract}
The aim was to test the null hypotheses that there is no difference: (1) in carious lesion development at the restoration margin between class II composite resin restorations in primary molars produced through the atraumatic restorative treatment (ART) with and without a chemomechanical caries removal gel and (2) in the survival rate of class II composite resin restorations between two treatment groups after 2 years. Three hundred twenty-seven children with 568 class II cavitated lesions were included in a parallel mouth study design. Four operators placed resin composite (Filtek Z 250) restorations bonded with a selfetch adhesive (Adper prompt L pop). Two independent examiners evaluated the restorations after $0.5,1$, and 2 years using the modified Ryge criteria. The Kaplan-Meier survival method was applied to estimate survival percentages. A high proportion of restorations were lost during the study period. Therefore, the first hypothesis could not be tested. No statistically significant difference was observed between the cumulative survival percentages of restorations produced by the two treatment approaches over the 2-year period (ART, 54.1 $\pm 3.4 \%$; ART with Carisolv ${ }^{\mathrm{TM}}, 46.0 \pm$ $3.4 \%$ ). This hypothesis was accepted. ART with chemomechanical gel might not provide an added benefit
\end{abstract}

\footnotetext{
A. Topaloglu-Ak $\cdot$ E. Eden $\cdot$ O. Oncag

Department of Pediatric Dentistry, Ege University,

School of Dentistry,

Izmir, Turkey

J. E. Frencken $(\triangle)$

Nijmegen International Centre for Oral Health, Radboud University Nijmegen Medical Centre, College of Dental Sciences,

P.O. Box 9101, 6500 HB Nijmegen, The Netherlands

e-mail: j.frencken@dent.umcn.nl
}

increasing the survival percentages of ART class II composite resin restorations in primary teeth.

Keywords Atraumatic restorative treatment. Composite resin · Primary molars .

chemomechanical caries removal gel · Adper prompt L pop

\section{Introduction}

Atraumatic restorative treatment (ART) is based on removing demineralized dental tissues using hand instruments only and filling the cavity and associated pit and fissures with an adhesive material, generally a glass ionomer [16]. This treatment approach was initially developed to provide preventive and restorative care to people in low-income countries. However, the use of ART is no longer restricted to underprivileged nations. Seale and Casamassimo [37] reported that $44 \%$ of USA general dental practitioners often used ART as a restorative procedure to treat children restoratively, whereas Burke et al. [9] reported that nearly $10 \%$ of general dental practitioners in England and Scotland had adopted ART to treat children restoratively. In The Netherlands, ART was used by $26 \%$ of general dental practitioners mainly to treat children and anxious adults [8]. Since the utilization of ART for treating carious lesions began gaining acceptance by an ever-increasing number of dental professionals, not only glass ionomers but also resinbased restorative materials have been used with ART. The resin-based materials have been used particularly in primary teeth $[10,14,20,22]$.

The study by Eden et al. [10] showed low survival rates for self-etched multiple-surface composite resin restorations produced in primary molars through ART as well as through 
the traditional treatment approach. The poor performance of the self-etched primer system was considered the main reason for failure in both approaches. However, despite the fact that low levels of bacterial load have been found in cavities cleaned using ART [6], it is conceivable that some infected dentine may have been left behind, hindering a proper bonding of the self-etch primer to tooth tissues.

ART has been well accepted by children $[34,36]$ and adults [24] as a largely pain-free caries management approach in comparison to the traditional approach. The absence of the drill and the low level of necessity to administer local anesthesia have contributed to its acceptance. These conditions are essential in the search for a caries management method with the potential to improve the removal of infected dentin, and thus reducing the chance for carious lesion development at the restoration margin, using hand instruments as part of the ART approach. One such method involves the use of the chemomechanical caries removal gel.

In applying this gel, infected dentine is selectively removed by softening it while preserving the affected dentine. The most recently developed chemomechanical caries removal gel, Carisolv ${ }^{\mathrm{TM}}$, has been proven to be effective [18, 27, 28, 31]. Specially provided blunt hand instruments are required in combination with rotary instruments for providing access to the dentin lesion. Like ART, the use of the chemomechanical caries removal gel appears to offer a relatively painless and comfortable treatment, well accepted by child patients attending pediatric clinics $[2,4,21]$. Tooth surfaces treated with Carisolv ${ }^{\mathrm{TM}}$ were sufficiently cleaned of carious tooth tissues to allow good adhesion of composite resin material [12, 44].

To date, several studies have compared the carious-tissueremoving effects of chemomechanical caries removal gel and hand instruments in vivo [21, 28, 44]. However, in these studies, the openings of the cavities were wide or access to the cavities was obtained through use of a drill. In none was chemomechanical caries removal gel applied in cavities that had to be opened with hand instruments (ART).

The null hypotheses tested were: (1) there is no difference in percentage of carious lesion development at the restoration margin between class II composite resin restorations in primary molars produced through the ART approach and those treated using ART in combination with a chemomechanical caries removal gel and (2) there is no difference in the survival rate of class II composite resin restorations in primary molars among children of the two treatment groups after 2 years.

\section{Materials and methods}

Sampling procedure The sample size calculation was based on a difference in percentage of failures due to carious lesion development at the restoration margin after a 2-year follow-up period, of $10 \%$ [10] versus $4 \%$ for ART without, and with a chemomechanical caries removal gel (ART+CCR), respectively, at an $\alpha=5 \%$ with a power of $80 \%$. This resulted in the need for 280 restorations per treatment group. Taking into account a dropout rate of $10 \%$ after 2 years and $15 \%$ additional restorations for the dependency of restorations per child in a parallel group study design, the number of restorations required was 350 per group. On the basis of two suitable cavitated molars on average per child, it was calculated that 175 children per group were required to test the first hypothesis of the present study.

Approval to conduct the clinical study was obtained from the Ethical Committee of Ege University in Izmir, Turkey (03-11/7M-599). A letter requesting informed consent was given to each of the subjects. Only those whose parents or guardians had signed and returned letters were included in the study.

The subjects were 6- to 7-year-old children who had at least one class II cavitated dentine lesion in a primary molar. The only lesions included in the study were class II cavitated dentine lesions with an opening wide enough for the ART excavator $(\varnothing=0.9 \mathrm{~mm})$ to penetrate and no pulp involvement. Children were provided with proper oral hygiene instructions and received all other necessary oral care.

Implementation A parallel study design was used. The cavitated dentin lesions were randomly assigned to one of the treatment groups after stratification for gender, operator, upper/lower jaw and, when needed, according to left/right side of the mouth using a validated computer software program (Trial Balance, Lausanne, Switzerland). The clinical treatment was performed by four dentists (two senior and two junior) in the dental clinic of the Department of Pediatric Dentistry during April and November of 2003. Both senior dentists were experienced in ART, as they had participated in a related study [10]. Two junior dentists had been trained in ART by the seniors over 1 week. As all operators were unfamiliar with the use of Carisolv, a 1week training program was organized prior to the start of the study.

Treatment procedure The ART treatment procedure consisted of widening a small cavity opening or removing thin enamel in larger cavity openings with a dental hatchet $\mathrm{(Hu}-$ Friedy, Chicago, USA) until the enamel was free of visible demineralization and access to the cavity was established. Soft infected dentine was excavated from the cavity walls and floor with spoon excavators. A suction device and cotton-wool rolls were used to isolate the tooth. No local anesthesia was administered. An omni matrix (Ultradent Products Inc, South Jordan, USA) and inter-dental wooden 
wedges were placed before restoration. The self-etched adhesive, Adper Prompt L Pop (3MESPE, Seefeld, Germany), was applied using the supplied brush, rubbed for $20 \mathrm{~s}$, air-blown until it became thin, and light-cured with an LED (Elipar Freelight 2, 3MESPE) light source for $20 \mathrm{~s}$. The preparations were restored with a composite material, Filtek Z250 (3MESPE), in layers of approximately 2-mm thickness. Each increment was light-cured with the LED light source for $20 \mathrm{~s}$. The restoration was polished and biteadjusted using polishing strips.

Opening and widening of cavities treated through the ART procedure, in combination with a chemomechanical caries removal gel, were prepared in the same way as described for the ART procedure. After the cavity had been accessed, the chemomechanical caries removal gel (Carisolv $^{\mathrm{TM}}$, Mediteam, Sävedalen, Sweden) was applied in the cavity for $30 \mathrm{~s}$. The softened dentine was scraped away using the specially designed Carisolv ${ }^{\mathrm{TM}}$ hand instruments. Excess Carisolv ${ }^{\mathrm{TM}}$ gel was removed with wet cotton-wool pellets. Application of Carisolv ${ }^{\mathrm{TM}}$ gel continued until the gel stayed clear. The prepared cavities were restored and finished in the same way as described for the ART procedure.

The cavitated dentin lesions included were categorized according to a modification of the classification of the contact area of Mount and Hume [26] after the cavity preparation was completed. The three categorized sizes in the extension of a lesion were defined as: minimal (furthest occlusal cavity extension in area 1), moderate (furthest occlusal cavity extension in area 2), and large (furthest occlusal cavity extension in area 3; Fig. 1).

For both treatment approaches, a stopwatch was used to record the time needed to prepare and restore the cavities.

Evaluation Two calibrated independent examiners, who were blinded to the treatment method provided, evaluated the occlusal and aproximal parts of the restorations after

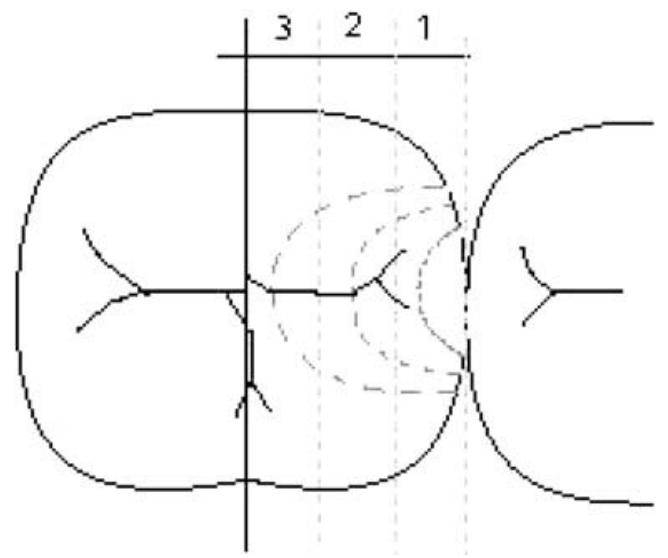

Fig. 1 Categorization of included cavities by size: minimal=1; moderate $=2 ;$ large $=3$
6 months, 1 year, and 2 years according to the modified Ryge criteria [35]. Examinations, using battery-powered headlights, took place on the school premises. A calibration session was carried out before the start of each evaluation period at the dental clinic of the Department of Pediatric Dentistry. Intra-examiner consistency test was carried out for diagnosing caries at the margin and assessing marginal integrity, anatomical form, and discoloration on 306 to 316 surfaces (unable to diagnose was excluded) using kappa statistics. The kappa value of the scores for the first evaluator for the four conditions was 1.0. The second evaluator had a kappa score of 1.0 for all conditions but for marginal integrity $(\kappa=0.78)$.

Statistical analysis All data were entered into the computer, checked for accuracy, and analyzed using SAS software by an oral biostatistician at the College of Dental Sciences, Radboud University Nijmegen, The Netherlands. The independent variables studied were gender, operator, type of jaw, type of molar, and cavity size. A restoration was considered to have survived if it scored alpha or bravo for anatomical form, marginal integrity, and marginal discoloration and if recurrent caries was not diagnosed. Presence of recurrent caries was given precedence over physical reasons for failures and marginal integrity was given preference over the other physical reasons in cases where a restoration failed for more than one reason. The data were censored owing to dropout and the restricted general follow-up period of 2 years. The Kaplan-Meier survival method was applied to estimate survival percentages. Owing to the dependency of data on different restorations in one child, the Greenwood approximation for the standard error (SE) of the survival percentages was not valid [1]. Therefore, the Jackknife method [11] (leaving one patient out) was applied in calculating the SEs. The log rank test for censored data was used to test the difference between the restoration survival percentages of both procedures and the effect of the independent variables on the survival percentages of both types of restoration.

Analysis of variance, after log transformation because of the skewness of data, was used to assess the effect of the independent variables on preparation and restoration time used for producing restorations through the two treatment procedures.

\section{Results}

Disposition of subjects and restorations A total of 327 children, $53 \%$ male and $47 \%$ female, participated. The mean age was $6.2(\mathrm{SD}=0.5)$ years. A total of 568 restorations were placed, of which $51 \%$ were in the upper jaw and $49 \%$ in the lower jaw, $65 \%$ in first primary molars 
and $35 \%$ in second primary molars. Moderate-size cavities were most frequently restored $(70 \%)$, followed by minimal $(25 \%)$ and large cavities $(5 \%)$.

The total number of restorations placed per child per treatment group is shown in Table 1. About 50\% of children in both groups had only one suitable cavitated primary molar.

Handling of longitudinal data Each of the 568 restorations was associated with a longitudinal series of evaluation scores. An interrupted longitudinal series was observed 131 times. This implied that at one or two evaluation years, a distinct moment of failure could not be specified. In such a situation, an intelligent decision was made as to which year of evaluation the failure was allocated. At evaluation year 1, 91 longitudinal series could not be interpretable clearly, resulting in 45 times failures allocated to evaluation year 0.5 and 46 times to evaluation year 1 . At evaluation year 2, 40 longitudinal series could not be interpretable clearly, resulting in allocating six failures to evaluation year 0.5 , 12 failures to evaluation year 1 , and 22 failures to evaluation year 2. This manner of handling of longitudinal data was performed proportionally for the treatment procedures.

Survival of restorations The cumulative survival percentages and Jackknife SE of class II composite restorations in primary molars prepared by ART and ART $+\mathrm{CCR}$ over the 2-year period are presented in Table 2. A borderline statistically significant difference in cumulative survival percentages between ART and ART+CCR was observed at evaluation year 2 only ( $t$ test; $p=0.046$ ). However, no statistically significant difference was observed between the cumulative survival percentages of restorations produced by the two treatment approaches over the 2-year period ( $p=$ $0.31)$. There was no gender $(p=0.2)$, no operator $(p=0.64)$, no type of jaw $(p=0.23)$, no type of molar $(p=0.66)$, and no cavity size (0.91) effect observed between the cumulative

Table 1 Number of restorations placed per child $(N)$ per treatment group

\begin{tabular}{lccccc}
\hline$N$ & \multicolumn{2}{c}{ ART } & & & \multicolumn{2}{c}{ ART $+\mathrm{CCR}$} \\
\cline { 2 - 3 } \cline { 6 - 6 } & $N_{\text {child }}$ & Percentage & & $N_{\text {child }}$ & Percentage \\
\hline 1 & 81 & 49.7 & & 80 & 48.5 \\
2 & 53 & 32.5 & & 64 & 38.8 \\
3 & 19 & 11.7 & & 14 & 8.5 \\
4 & 8 & 4.9 & & 5 & 3.0 \\
5 & 2 & 1.2 & & 1 & 0.6 \\
7 & - & & & 1 & 0.6 \\
Total & 163 & & 165 & \\
\hline
\end{tabular}

survival percentages of restorations produced by the two treatment procedures over the 2-year period.

Failure characteristics Table 3 shows the number of failed class II composite resin restorations by reason for failure, procedure, and time of evaluation. No restorations failed because of anatomical form or discoloration. A total number of 103 and 114 restorations failed in the ART and $\mathrm{ART}+\mathrm{CCR}$, respectively. The predominant reason why restorations failed was total loss of restorations (73\%), followed by marginal integrity $(15 \%)$ and carious lesion development at the restoration margin (12\%). At the three times of evaluation, there was no statistically significant difference between ART and ART $+\mathrm{CCR}$ regarding carious lesion development at the margin.

Working time The mean working time required to produce a class II restoration through ART $+\mathrm{CCR}$ and ART was $14.15 \pm 4.06$ and $13.58 \pm 3.55 \mathrm{~min}$, respectively (Table 4$)$. A procedure $(p=0.004)$, an operator $(p<0.0001)$, and a cavity size $(p=0.002)$ effect on cavity preparation time was observed. Preparing cavities with ART (6.76 min) was statistically significantly faster than with ART + CCR (7.53 $\mathrm{min})$. Large cavities $(8.16 \mathrm{~min})$ took longer to prepare than medium $(7.11 \mathrm{~min})$ and small cavities $(7.02 \mathrm{~min})$.

\section{Discussion}

Although particular attention was given to selecting schools with low pupil movement for subject selection, the percentage of the lost-to-follow-up, after 2 years, was high. This was mainly due to children's changing schools or being absent on the day of evaluation.

The power calculation was based on the assumption that a difference of $6 \%$ in carious lesion development at the restoration margin was considered clinically relevant and that two suitable cavities would be present per child. The later did not turn out to be the case. Almost $50 \%$ of the children in both treatment groups had only one suitable cavity. This finding had the advantage that the restoration survival scores were independent from each other for a large part of the data set, but had the disadvantage that the required sample size could not be fully met. To deal with the dependency of the restoration survival scores, the Jackknife method was applied, increasing the standard error in comparison to the one calculated as part of the Kaplan-Meier test. The calculated sample size could also not be met, as children who fulfilled the inclusion criteria were not available in sufficient numbers in the schools selected. As the study had to be implemented already in two periods, 7 months apart because of the low number of 
Table 2 Cumulative survival (\%) and Jackknife SE of class II composite restorations in primary molars prepared by ART with and without Carisolv (ART $+\mathrm{CCR})$ over a 2-year period

\begin{tabular}{|c|c|c|c|c|c|c|c|c|c|c|c|c|}
\hline \multirow[t]{3}{*}{ Interval years } & \multicolumn{6}{|l|}{ ART } & \multicolumn{6}{|c|}{$\mathrm{ART}+\mathrm{CCR}$} \\
\hline & \multirow[t]{2}{*}{$N_{\text {child }}$} & \multirow[t]{2}{*}{$N_{\text {entry }}$} & \multirow[t]{2}{*}{$N_{\text {censored }}$} & \multirow[t]{2}{*}{$N_{\text {failed }}$} & \multicolumn{2}{|l|}{ Survival } & \multirow[t]{2}{*}{$N_{\text {child }}$} & \multirow[t]{2}{*}{$N_{\text {entry }}$} & \multirow[t]{2}{*}{$N_{\text {censored }}$} & \multirow[t]{2}{*}{$N_{\text {failed }}$} & \multicolumn{2}{|l|}{ Survival } \\
\hline & & & & & Percentage & SE & & & & & Percentage & SE \\
\hline $0-0.5$ & 163 & 286 & 41 & 46 & 81.2 & 2.3 & 164 & 282 & 44 & 39 & 83.6 & 2.2 \\
\hline $0.5-1$ & 107 & 199 & 15 & 28 & 68.8 & 2.8 & 108 & 199 & 12 & 30 & 70.1 & 3.1 \\
\hline $1-2$ & 84 & 156 & 20 & 29 & $54.1 *$ & 3.4 & 85 & 157 & 26 & 45 & $46.0 *$ & 3.4 \\
\hline
\end{tabular}

$N_{\text {child }}$ number of children at start of interval, $N_{\text {entry }}$ number of restorations at start of interval, $N_{\text {censored }}$ number of restorations censored during interval, $N_{\text {failed }}$ number of restorations failed at end of interval

$* p=0.046$

eligible children in the first period, adding a third treatment period was considered not possible. To what extent the lower than calculated sample size has influenced the power of the study is open for debate. Authors had decided that a $6 \%$ difference in carious lesion development at the restoration margin in favor of Carisolv-treated cavities would be clinically relevant. However, if authors had decided that a $7 \%$ difference would be clinically relevant, a sample size of 438 restorations would be required, well within the total sampled population of the present study. In other words, a $1 \%$ difference in assumption of what is considered clinically significant provides a study with a poor or a high power. Therefore, we consider the current sample size suitable for analyzing the data and for testing the hypotheses.

In a move to increase the low survival rate after 2 years $(60 \%)$ of class II ART restorations using glass ionomers in multiple surface cavities in primary teeth [39], researchers had considered replacing glass ionomer by the more fracture-resistant composite resin. The change was triggered by the advent of self-etched adhesives that did not require the use of a pumped water system and electricity, a situation that favored the use of hand instruments (ART). Eden et al. [10] showed that it was possible to produce composite resin restorations in multiple surfaces in primary molars using hand instruments (ART) only. Unfortunately, the restorations failed early, presumably because of the poor adhesion of the self-etched adhesive (Prompt L-pop) used. The present study was a follow-up to the study conducted by Eden et al. [10] using an improved version of the former self-etched adhesive (Adper Prompt L Pop). The present study showed again that composite restorations in multiplesurface cavities in primary molars could be produced with hand instruments only. But it was unable to show high survival results for both treatment groups.

The predominant reason for restoration failure in both treatment groups was complete loss of restoration. Unfortunately, the newly developed self-etched adhesive is most probably the reason for the high number of failures due to total loss of restorative material observed in the present study. The prevalence of carious lesion development at the restoration margin did not differ between the two treatment groups over the 2-year test period. However, it is noteworthy that because many restorations had failed after 6 and 12 months, the number of eligible teeth that could become carious had decreased substantially and this, consequently, had reduced the power of the study. It is therefore appropriate to conclude that the present investigation was unable to test whether the use of a chemomechanical caries removal gel offers added value in the process of using ART to manage multiple-surface cavities in primary molars. Hence, the first hypothesis could not be tested.

Table 3 Number of failed class II composite resin restorations by reason for failure, procedure, and time of evaluation

\begin{tabular}{|c|c|c|c|c|c|c|c|c|c|c|c|c|c|c|c|c|}
\hline \multirow{3}{*}{ Time of evaluation } & \multicolumn{8}{|c|}{ ART } & \multicolumn{8}{|c|}{$\mathrm{ART}+\mathrm{CCR}$} \\
\hline & \multicolumn{2}{|l|}{0.5} & \multicolumn{2}{|l|}{1} & \multicolumn{2}{|l|}{2} & \multicolumn{2}{|c|}{ Total } & \multicolumn{2}{|l|}{0.5} & \multicolumn{2}{|l|}{1} & \multicolumn{2}{|l|}{2} & \multicolumn{2}{|c|}{ Total } \\
\hline & $N$ & Percentage & $N$ & Percentage & $N$ & Percentage & $N$ & Percentage & $N$ & Percentage & $N$ & Percentage & $N$ & Percentage & $N$ & Percentage \\
\hline $\begin{array}{l}\text { Dentine lesion } \\
\text { development }\end{array}$ & 2 & 9 & 2 & 5 & 8 & 22 & 12 & 12 & 2 & 18 & 4 & 8 & 8 & 15 & 14 & 12 \\
\hline Marginal integrity & 4 & 17 & 11 & 26 & 6 & 16 & 21 & 20 & 0 & 0 & 5 & 10 & 6 & 11 & 11 & 10 \\
\hline Total loss of restoration & 17 & 74 & 30 & 69 & 23 & 62 & 70 & 68 & 9 & 82 & 39 & 81 & 41 & 74 & 89 & 78 \\
\hline Total & 23 & & 43 & & 37 & & 103 & 100 & 11 & & 48 & & 55 & & 114 & 100 \\
\hline
\end{tabular}


Table 4 Mean working time (min) and \pm SD needed to place restorations produced with ART and ART with a chemomechanical caries removal gel $(\mathrm{ART}+\mathrm{CCR})$ in class II cavities of primary molars by preparation and restoration procedure and by operator

\begin{tabular}{|c|c|c|c|c|c|c|}
\hline \multirow[t]{2}{*}{ Operator } & \multicolumn{2}{|l|}{ Cavity preparation } & \multicolumn{2}{|c|}{ Restorative procedure } & \multicolumn{2}{|l|}{ Total } \\
\hline & $\mathrm{ART}$ mean $\pm \mathrm{SD}$ & $\mathrm{ART}+\mathrm{CCR}$ mean $\pm \mathrm{SD}$ & $\mathrm{ART}$ mean $\pm \mathrm{SD}$ & $\mathrm{ART}+\mathrm{CCR}$ mean $\pm \mathrm{SD}$ & $\mathrm{ART}$ mean $\pm \mathrm{SD}$ & $\mathrm{ART}+\mathrm{CCR}$ mean $\pm \mathrm{SD}$ \\
\hline 1 & $7.15 \pm 2.17$ & $8.39 \pm 2.75$ & $6.40 \pm 1.89$ & $6.29 \pm 1.85$ & $13.56 \pm 3.17$ & $14.66 \pm 3.86$ \\
\hline 2 & $6.82 \pm 2.28$ & $7.10 \pm 2.09$ & $7.12 \pm 2.04$ & $6.51 \pm 1.77$ & $13.94 \pm 3.70$ & $13.61 \pm 3.32$ \\
\hline 3 & $6.54 \pm 2.18$ & $6.71 \pm 2.49$ & $6.70 \pm 2.27$ & $7.01 \pm 3.06$ & $13.23 \pm 3.37$ & $13.74 \pm 4.89$ \\
\hline 4 & $6.73 \pm 2.92$ & $8.43 \pm 2.84$ & $7.14 \pm 2.04$ & $6.50 \pm 1.69$ & $13.87 \pm 4.09$ & $14.90 \pm 3.39$ \\
\hline All & $6.76 \pm 2.36$ & $7.53 \pm 2.64$ & $6.82 \pm 2.11$ & $6.63 \pm 2.30$ & $13.58 \pm 3.55$ & $14.15 \pm 4.06$ \\
\hline
\end{tabular}

The second hypothesis tested was that the survival rate of the composite resin restorations in cavities prepared by ART with and ART without Carisolv ${ }^{\mathrm{TM}}$ would show no difference. The hypothesis was tested in two ways: (1) over the 2-year period using the log rank method and (2) per year of evaluation using the $t$ test. This was done to enable determination of a survival trend in the two sets of restorations and to assess a restoration survival difference per year of evaluation. This move was governed by the fact that many restorations were censored and many had failed. Although a borderline statistically significant difference between the two treatment groups was observed at the second year of evaluation, it was concluded that no significant difference in survival rates exists between class II composite resin restorations prepared by ART and ART+CCR in primary molars after 2 years. The second hypothesis was therefore accepted.

The survival rates of multiple-surface composite resin restorations in primary molars produced using hand instruments in the present study and in a previous one [10] were low, necessitating discussion on reasons for failure. In general, self-etched adhesives provide simple and fast bonding of composite resin to tooth tissues. Adper prompt $\mathrm{L}$ pop consists of a single dose with three compartments that have to be mixed precisely to become effective. However, if effective mixing is not accomplished, some part of liquid may stay in the compartments and result in an incorrectly mixed adhesive, which may lead to poor adhesion [25]. All operators in the present study were instructed to handle the mixing procedure correctly before the study started. Taking into account the absence of an operator effect in the survival percentages of both types of treatment, it is unlikely that improper mixing was a major reason for the high number of restorations observed as completely lost. Another reason for the high rate of complete loss of restorations may be related to the solvent in the self-etched adhesive used. In contrast to self-etched adhesives using ethanol, Adper prompt L pop contains water, which does not evaporate and may, therefore, be left behind at the adhesive interface and cause poor adhesion to tooth tissues [25, 40].
It has also been demonstrated that the use of Adper prompt L Pop resulted in lower bond strengths to both enamel and dentine compared to a two-step etch-and-rinse system [43]. The microleakage scores of composite resin restorations with Adper prompt L pop were also lower than those using total etch-and-rinse systems [7, 19]. Therefore, in contrast to the anticipated positive effect of its high initial acidity $(\mathrm{pH}=0.8)$, the shearbond strengths of Adper prompt L pop on dentine were unsatisfactory compared to mild acidic self-etching systems [25]. The enamel thickness in primary teeth is thinner than in permanent teeth, so an even lower adhesion of Adper prompt L pop (and for that matter, all other self-etched adhesive systems) could be expected in restorations produced in primary than in permanent teeth.

The directions for use instruct the operator to create a thin layer of adhesive that is achieved through careful air blowing. Estimating the resulting thickness of the layer is very difficult. It has been reported that a thick layer of adhesive is preferable to a thin layer [29]. The operators in the present study checked the walls and floor of the cavity for a shiny appearance before composite resin material was applied. If a dull appearance was seen, an additional layer of adhesive was applied. We think therefore that the adhesive application procedure followed in the present study was according to standard and is not considered a main reason for the high number of failures observed.

There are, unfortunately, only a few studies that have tested the survival of restorations bonded with Adper prompt L pop. Bittencourt et al. [5] showed high survival results of composite resin restorations using Adper prompt L pop in non-carious cervical lesions after 18 months. Although the clinical performance of posterior composite restorations using Adper prompt L pop in premolars and molars was worse than that of similar restorations using other self-etched adhesives after 1 year [30], the results were not as bad as those observed in the present study. The cause of the lower than expected survival results in the present study is not known. The operators were trained pediatricians, the materials were used according to the manufacturer's directions for use, the bite was adjusted 
properly so that occlusal forces had only a physiological effect on the bonding of the restorations, and care was taken to remove all infected dentine from the cavities, which is expected to be achieved particularly in those treated with the chemomechanical caries removal gel.

Self-etched adhesives have an advantage above the use of total etch-and-rinse systems, particularly in children, and manufacturers have launched improved versions of the adhesive in recent years. For example, class II ART restorations using composite resin bonded with a selfetched adhesive (Xeno III) in primary molars were compared with restorations using a high-viscosity glass ionomer [14]. After 2 years, no significant difference was found in the cumulative survival rates of the two types of restoration. The 2-year cumulative survival rate of class II ART composite restorations using Xeno III was much higher (88\%) [14] than that of the present study (54\%) using Adper prompt L pop and that of the previous study (35\%) using Prompt L pop [10]. The finding is remarkable, as the study by Ersin et al. [14] was done in school compounds, while the present study and the previous one were conducted in a dental clinic. As in the present study, Ersin et al. [14] used an LED light curing source for the polymerization of the adhesive. However, the difference in success between the three studies might be due to the different restorative materials used. Ersin et al. [14] used a packable resin composite, while the other two studies used hybrid composite resin. Packable composite resins are known to have a lower wear resistance, reduced polymerization shrinkage, increased surface hardness, and a higher resistance to fracture than those of the hybrid composites [33, 41]. Use of a newly developed self-etch adhesive might also have contributed. Xeno III bonded composite resin restorations in non-carious cervical lesions revealed a $96 \%$ retention of the restorations after 1 year [42].

Laboratory tests have shown unfavorable features of self-etched adhesives compared to two-step and total etchand-rinse adhesive systems. Simplicity, therefore, does not necessarily imply improved bonding performance [38]. This conclusion is in line with the results of a systematic review on clinical trials using adhesives in non-carious class V lesions, which showed insufficient clinical performance of one-step self-etched adhesives [32].

Time needed to prepare the cavity is an important issue in pediatric dentistry. Although the present study was unable to reach conclusions regarding the added value of chemomechanical removal of carious tissues within the ART philosophy, it did, however, show that removal of carious tissues through ART alone took, on average, less time than ART aided with a chemomechanical caries removal gel. This finding corroborates reports covering the use of chemomechanical caries removal techniques in comparison with rotary instruments $[3,13,15,17]$. It was reported that the longer working time of chemomechanical caries removal gel had a negative effect on children and that they preferred the conventional treatment modality [23].

In conclusion, within the limitations of this study, after 2 years, no statistically significant difference in clinical success was found between the two treatment modalities under study. The predominant failure for both treatment modalities was total loss of restorations. Using a chemomechanical caries removal gel in ART might not provide an added benefit to the ART approach, as it requires a longer treatment time.

Acknowledgments We are very grateful to Dr. A. Ozen for his participation as one of the operators, Prof. W. van Palenstein Helderman for taking part in the evaluation process, and to Ir. Jan Mulder for analyzing the data.

Conflict of interest Authors declare that they have no conflict of interest.

Open Access This article is distributed under the terms of the Creative Commons Attribution Noncommercial License which permits any noncommercial use, distribution, and reproduction in any medium, provided the original author(s) and source are credited.

\section{References}

1. Altman DG (1999) Practical statistics for medical research. CRC, Boca Raton, p 379

2. Ansari G, Beeley JA, Fung DF (2003) Chemomechanical caries removal in primary teeth in a group of anxious children. J Oral Rehab 30:773-779

3. Banarjee A, Kidd EAM, Watson TF (2000) In vitro evaluation of five alternative methods of carious dentine excavation. Caries Res $34: 144-150$

4. Bergmann J, Leitao J, Kultje C, Bergmann D, Glode MJ (2005) Removing dentine caries in deciduous teeth with Carisolv: a randomised, controlled, prospective study with six-month followup, comparing chemomechanical treatment with drilling. Oral Health Prev Dent 3:105-111

5. Bittencourt DD, Ezecelevski IG, Reis A, van Dijken JWV, Loguercio AD (2005) An 18-months' evaluation of self-etch and etch $\&$ rinse adhesive in non-carious cervical lesions. Acta Odont Scand 63:173-178

6. Bönecker M, Toi C, Cleaton-Jones P (2003) Mutans streptococci and lactobacilli in carious dentine before and after atraumatic restorative treatment. J Dent 31:423-428

7. Brackett MG, Brackett WW, Haisch LD (2006) Microleakage of class V resin composites placed using self-etching resins: effect of prior etching. Quintessence Int 37:109-113

8. Bulut T, Sharif S (2004) Atraumatic restorative treatment in Nederland. Dissertation, College of Dental Sciences, Nijmegen

9. Burke FJ, McHugh S, Shaw L, Hosey MT, Macpherson L, Delargy S, Dopheide B (2005) UK dentists' attitudes and behaviour towards atraumatic restorative treatment for primary teeth. Br Dent J 199:365-369

10. Eden E, Topaloglu-Ak A, Frencken JE, Van't Hof MA (2006) Survival of self etched class II composite restorations using ART and conventional cavity preparations in primary molars. Am J Dent 19:359-363 
11. Effron B (1979) Bootstrap methods: another look at the jackknife. Ann Stat 7:1-26

12. Emanuel R, Broom JC (1988) Surface energy of chemomechanically prepared dentin. Quintessence Int 19:369-372

13. Ericson D, Zimmerman M, Raber H, Gotrick B, Bornstein R, Thorell J (1999) Clinical evaluation of efficacy and safety of a new method for chemo-mechanical removal of caries. Caries Res $33: 171-177$

14. Ersin NK, Candan U, Aykut A, Oncag O, Eronat C, Kose T (2006) A clinical evaluation of resin-based composite and glass ionomer cement restorations placed in primary teeth using the ART approach. J Am Dent Assoc 137:1529-1536

15. Flückiger L, Waltimo T, Stich H, Lussi A (2005) Comparison of chemomechanical caries removal using Carisolv or conventional hand excavation in deciduous teeth in vitro. J Dent 33:87-90

16. Frencken JE, Pilot T, Songpaisan Y, Phantumvanit P (1996) Atraumatic restorative treatment (ART): rationale, technique and development. J Public Health Dent 56:135-140

17. Fure S, Lingström P, Birkhed D (2000) Evaluation of Carisolv for the chemomechanical removal of primary tooth caries in vivo. Caries Res 34:275-280

18. Fure S, Lingström P (2004) Evaluation of the chemomechanical removal of dentine caries in vivo with a new modified Carisolv gel. Clin Oral Investig 8:139-144

19. Guéders AM, Charpentier JF, Albert AI, Geerts SO (2006) Microleakage after thermocycling of 4 etch and rinse and 3 selfetch adhesives with and without a flowable composite lining. Oper Dent 31:450-455

20. Honkala E, Behbehani J, Ibricevic H, Kerosuo E, Al-Jame G (2003) The atraumatic restorative treatment (ART) approach to restoring primary teeth in a standard dental clinic. Int $\mathbf{J}$ Paediatr Dent 13:172-179

21. Kirzioglu Z, Gurbuz T, Yilmaz Y (2007) Clinical evaluation of chemomechanical and mechanical caries removal: status of the restorations at 3, 6, 9 and 12 months. Clin Oral Invest 11:69-76

22. Louw AJ, Sarvan I, Chikte UME, Honkala E (2002) One year evaluation of atraumatic restorative treatment and minimal intervention techniques on primary teeth. S Afr Dent J 57:336371

23. Maragakis GM, Hahn P, Hellwig E (2001) Clinical evaluation of chemomechanical caries removal in primary molars and its acceptance by patients. Caries Res 35:205-210

24. Mickenautsch S, Frencken JE, van't Hof MA (2007) Atraumatic restorative treatment and dental anxiety in outpatients attending public oral health clinics in South Africa. J Public Health Dent 67:179-184

25. Miranda C, Prates LHM, Vieira RS, Calvo MCM (2006) Shear bond strength of different adhesive system to primary dentin and enamel. J Clin Peadiatr Dent 31:35-40

26. Mount GJ, Hume WR (1997) A revised classification of carious lesions by site and size. Quintessence Int 28:301-303

27. Munshi AK, Hedge AM, Shetty PK (2001) Clinical evaluation of Carisolv in the chemo-mechanical removal of carious dentin. $\mathbf{J}$ Clin Pediatr Dent 26:49-54
28. Nadanovsky P, Cohen Carneiro F, Souza de Mello F (2001) Removal of caries using only hand instruments: a comparison of mechanical and chemo-mechanical methods. Caries Res 35:384389

29. Pashley EL, Agee KA, Pashley DH, Tay FR (2002) Effect of one versus two applications of an unfilled, all-in-one adhesive on dentine bonding. J Dent 30:83-90

30. Perdigao J, Dutra Correa M, Castilhos N, Carmo RPA, AnauateNetto C, Cordeiro JDH, Amore R, Lewgoy HR (2007) One year clinical performance of self etch adhesives in posterior restorations. Am J Dent 20:125-133

31. Peric T, Markovic D (2007) In vitro effectiveness of a chemomechanical method for caries removal. Eur J Paediatr Dent 8:6167

32. Peumans M, Kanumilli P, De Munck J, Van Landuyt K, Lambrechts P, Van Meerbeek B (2005) Clinical effectiveness of contemporary adhesives: a systematic review of current clinical trials. Dent Mater 21:864-881

33. Poon EC, Smales RJ, Yip KH (2005) Clinical evaluation of packable and conventional hybrid posterior resin based composites: results at 3.5 years. J Am Dent Assoc 136:1533-1540

34. Rahimtoola S, van Amerongen E, Maher R, Groen H (2000) Pain related to different ways of minimal intervention in the treatment of small caries lesions. J Dent Child 67:123-127

35. Ryge G (1980) Clinical criteria. Int Dent J 30:347-358

36. Schriks MCM, Van Amerongen WE (2003) Atraumatic perspective of ART. Psychological and physiological aspects of treatment with and without rotary instruments. Community Dent Oral Epidemiol 31:15-20

37. Seale SN, Casamassimo PS (2003) Access to dental care for children in the United States. A survey of general practitioners. J Am Dent Assoc 134:1630-1640

38. Shirai K, De Munck J, Yoshida Y, Inoue S, Lambrechts P, Suzuki K, Shintani H, Van Meerbeek B (2005) Effect of cavity configuration and aging on the bonding effectiveness of six adhesives to dentin. Dent Mater 21:110-124

39. Taifour D, Frencken JE, Beiruti N, Van't Hof MA, Truin GJ (2002) Effectiveness of glass-ionomer (ART) and amalgam restorations in the deciduous dentition-results after 3 years. Caries Res 36:437-444

40. Tay FR, Pashley DH, Suh BI, Carvalho RM, Itthagarun A (2002) Single-step adhesives are permeable membranes. J Dent 30:371-382

41. Turkun SL (2003) Clinical evaluation of a self etching and a one bottle adhesive system at two years. J Dent 31:527-34

42. Turkun LS (2005) The clinical performance of one- and two-step self-etching adhesive systems at one year. J Am Dent Assoc 136:656-664

43. Van Meerbeek B, De Munck J, Yoshida Y, Inoue S, Vargas M, Vijay P (2003) Current status and future challenges. Oper Dent 28:215-235

44. Yamada Y, Kimura Y, Hossain M Kinoshita JI, Shimizu Y, Matsomoto K (2005) Caries removal with Carisolv system: criteria evaluation and microleakage test. J Clin Pediatr Dent 30:121-126 